\title{
Cardiac volumes can be quantified accurately during free-breathing in young patients with congenital heart disease by cardiovascular magnetic resonance
}

\author{
Ahmed E Kharabish ${ }^{1 *}$, Naira Mkrtchyan ${ }^{1}$, Christian Meierhofer ${ }^{1}$, Stefan Martinoff ${ }^{2}$, Peter Ewert ${ }^{1}$, Heiko Stern ${ }^{1}$, \\ Sohrab Fratz ${ }^{1}$
}

From 17th Annual SCMR Scientific Sessions

New Orleans, LA, USA. 16-19 January 2014

\section{Background}

Cardiovascular Magnetic Resonance (CMR) with respiratory commands is the gold standard technique to measure cardiac volumes. Although cardiac volumes can be measured during free breathing in patients with congenital heart disease (CHD), its accuracy is unknown. Therefore, the aim of this study was to compare cardiac volumes acquired during free breathing with volumes acquired during breath hold commands.

\section{Methods}

Cardiac volumes were measured in every patient using both free breathing and breath hold techniques, by a routine standard steady state free precession (SSFP) cine sequence in axial slice orientation. The sequence parameters were always identical besides the number of averages being three during free breathing and one during breath holds. Volumes were determined in a blinded fashion by endocardial contouring and then correlated using the coefficient of determination and compared by Bland Altman analysis. Eleven younger patients with CHD aged median 4 yrs, range 3 months$14 \mathrm{yrs}$, were examined under general anesthesia and intubation (intubated younger patient group). Twelve older patients with CHD aged median 20 yrs, range 1161 yrs were examined consciously (conscious older patient group).

'Pediatric Cardiology and Congenital Heart Defects, German Heart Center, Munich, German

Full list of author information is available at the end of the article

\section{Results}

The agreement of the end systolic volume (ESV) and end diastolic volumes (EDV) between scanning with and without respiratory commands in both ventricles was excellent in the intubated younger patients (LVEDV: $\mathrm{r} 2=$ 0.98, LVESV: $\mathrm{r} 2=0.99$, RVEDV: $\mathrm{r} 2=0.99$, RVESV: $\mathrm{r} 2=$ 0.99 ) and less acceptable in the consciously examined

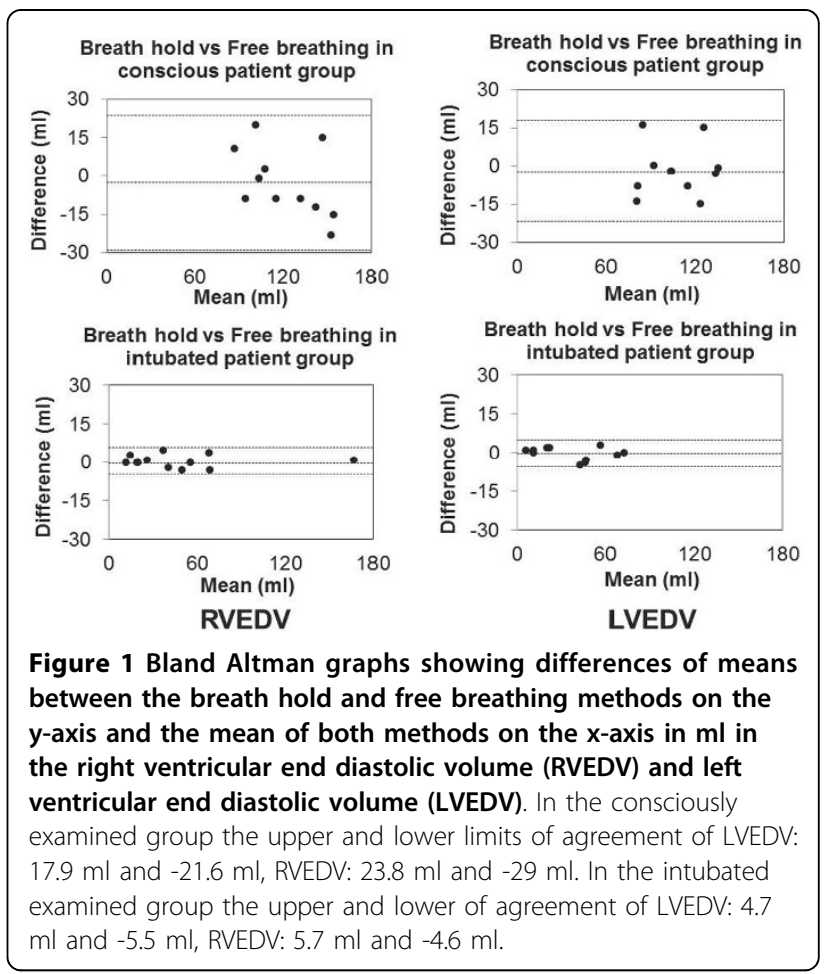


older patients (LVESV: $\mathrm{r} 2=0.87$, LVEDV: $\mathrm{r} 2=0.78$, RVESV: $\mathrm{r} 2=0.84$ and RVEDV: $\mathrm{r} 2=0.84)($ see Figure 1$)$.

\section{Conclusions}

Cardiac volumes can be quantified very accurately during free-breathing in young patients with congenital heart disease by CMR using standard routine imaging techniques. If needed, even in older patients cardiac volumes can be quantified reasonably accurate during free-breathing. Therefore, free-breathing is an alternative technique for patients not able to hold their breath and thus obliterating the need of anesthesia for many patients undergoing CMR. In addition it will provide a chance for the CMR to assess the hemodynamics in a resting physiologic condition.

\section{Funding}

All authors have no conflict of interest.

\section{Authors' details}

'Pediatric Cardiology and Congenital Heart Defects, German Heart Center, Munich, German. ${ }^{2}$ Radiology and Nuclear Medicine, German Heart Center, Munich, Germany.

Published: 16 January 2014

doi:10.1186/1532-429X-16-S1-P124

Cite this article as: Kharabish et al:: Cardiac volumes can be quantified accurately during free-breathing in young patients with congenital heart disease by cardiovascular magnetic resonance. Journal of Cardiovascular Magnetic Resonance 2014 16(Suppl 1):P124.

Submit your next manuscript to BioMed Central and take full advantage of:

- Convenient online submission

- Thorough peer review

- No space constraints or color figure charges

- Immediate publication on acceptance

- Inclusion in PubMed, CAS, Scopus and Google Scholar

- Research which is freely available for redistribution

Submit your manuscript at www.biomedcentral.com/submit 